\title{
Structural and Electronic Information on Two Solid Iminophosphoranes, Obtained from NMR
}

\author{
Julian C. Cherryman, Robin K. Harris ${ }^{\dagger}$, Matthew G. Davidson, \\ and Richard D. Price
}

Department of Chemistry, University of Durham, South Road,

Durham DH1 3LE, England

\begin{abstract}
Neste trabalho foram obtidos os espectros de RMN CPMAS de fósforo-31 e carbono-13 do imino(trifenil)fosforano e do brometo de amino(trifenil)fosfônio. A análise detalhada desses espectros forneceu informações sobre o tensor de blindagem de ${ }^{31} \mathrm{P}$ e o tensor de acoplamento quadrupolar de ${ }^{14} \mathrm{~N}$. O espectro estático de ${ }^{31} \mathrm{P}$ do brometo foi também analisado em termos dos tensores relevantes. Os cálculos ab initio no nível hf/6-31g* reproduzem bem os dados observados, com exceção dos deslocamentos isotrópicos, os quais requerem cálculos com bases maiores e/ou de um nível teórico superior. As orientações dos tensores na estrutura do brometo foram derivadas através dos cálculos.
\end{abstract}

Phosphorus-31 and carbon-13 CPMAS NMR spectra have been obtained for imino(triphenyl)phosphorane and amino(triphenyl)phosphonium bromide. Detailed analysis yields information about the ${ }^{31} \mathrm{P}$ shielding tensor and the ${ }^{14} \mathrm{~N}$ quadrupole coupling tensor. The static ${ }^{31} \mathrm{P}$ spectrum of the bromide was also analysed in terms of the relevant tensors. A $b$ initio calculations at the hf/6-31g* level reproduce the observed data well, except for the isotropic shifts, which require a larger basis set and/or higher level of theory. The orientations of the tensors in the molecular frame are derived for the bromide from the calculations.

Keywords: magic-angle spinning, iminophosphorane, ab initio calculation, shielding tensor

\section{Introduction}

Unsubstituted iminophosphoranes of the general formula $\mathrm{R}_{3} \mathrm{P}=\mathrm{NH}$ are isoelectronic to phosphorus ylides $\left(\mathrm{R} 3 \mathrm{P}=\mathrm{CH}_{2}\right)$. Whereas the latter have been extensively studied, the former have only relatively recently come to prominence, but they are expected to have similar properties to ylides. Of particular interest to us is their use as stronger ligands to s-block metals ${ }^{1}$ than ylides. We report here detailed solid-state NMR studies of imino(triphenyl)phosphorane, $\mathrm{Ph}_{3} \mathrm{P}=\mathrm{NH}(\mathbf{1})$, and its hydrobromide salt, $\left(\mathrm{Ph}_{3} \mathrm{P}-\right.$ $\left.\mathrm{NH}_{2}\right)^{+} \mathrm{Br}^{-}(2)$. Previous related NMR work ${ }^{2,3}$ has examined $\mathrm{N}$-aryl(triphenyl)iminophosphoranes and the isoelectronic series $\mathrm{R}_{3} \mathrm{P}=\mathrm{X}\left(\mathrm{X}=\mathrm{BH}_{3}, \mathrm{CH}_{2}, \mathrm{NH}, \mathrm{O}\right)$, but the authors concentrated on the ${ }^{31} \mathrm{P}$ nucleus, whereas herein we demonstrate that, in addition, information from ${ }^{13} \mathrm{C}$ (and indirectly ${ }^{14} \mathrm{~N}$ ) provides further insight into the electronic nature of these molecules. Phosphorus-31 shielding tensors have also been reported for iminophosphines involving $\mathrm{P}(\mathrm{III})$ (i.e. $\mathrm{X}-\mathrm{P}=\mathrm{E}$ with $\mathrm{X}$ an electronegative ligand and
$\mathrm{E}=\mathrm{CR}_{2}{ }_{2}$, NR' and PR') - see Ref. 4 and references therein. Both our compounds have been structurally characterized by diffraction methods ${ }^{5,6}$. The resulting information allows dipolar coupling constants to be calculated, and these have been used in subsequent analysis of NMR spectra. We have also used the crystal structures as the basis for $a b$ initio calculations of the shielding and quadrupolar tensors. A full understanding of the NMR spectra is then possible. The feasible electronic structures for the compounds are as below:

$$
\begin{gathered}
\mathrm{Ph}_{3} \mathrm{P}=\mathrm{NH} \leftrightarrow \mathrm{Ph}_{3} \mathrm{P}^{+}-\mathrm{N}^{-} \mathrm{H} \\
\mathbf{1} \\
\left(\mathrm{Ph}_{3} \mathrm{P}^{+}-\mathrm{NH}_{2}\right) \mathrm{Br}^{-} \leftrightarrow\left(\mathrm{Ph}_{3} \mathrm{P}=\mathrm{N}^{+} \mathrm{H}_{2}\right) \mathrm{Br}^{-} \\
\mathbf{2}
\end{gathered}
$$

\section{Experimental}

The samples of imino(triphenyl)phosphorane (1) and amino(triphenyl)phosphonium bromide (2) were prepared 
in Durham as part of a wide-ranging study of s-block metal derivatives of iminophosphoranes ${ }^{1}$. The bromide salt is air-stable and was therefore readily handled for packing into magic-angle rotors. The phosphorane is only moderately air-stable, so it was sealed under dry, oxygen-free argon in a glass ampoule which fits closely into a rotor (with packing of PTFE tape). However, on occasion, for short-term work, it was packed into a tightly-capped kel-F plastic insert which in turn fitted inside a rotor.

Phosphorus-31 and carbon-13 spectra were obtained at 81.015 and 50.329 MHz respectively, using a Chemagnetics CMX 200 spectrometer operating at ambient probe temperature. Zirconia rotors were used $(7.5 \mathrm{~mm}$ o.d. for the double-resonance experiments and $5.0 \mathrm{~mm}$ o.d. for the triple-resonance work on ${ }^{13} \mathrm{C}$ ). Cross-polarization from protons was employed, together with high-power proton decoupling during signal acquisition. A nitrogen-15 CPMAS spectrum (again with proton decoupling) was measured using a Varian UnityPlus 300 spectrometer at $30.399 \mathrm{MHz}$ and ambient probe temperature. Chemical shifts for ${ }^{13} \mathrm{C},{ }^{15} \mathrm{~N}$ and ${ }^{31} \mathrm{P}$ were measured by replacement via the signals for adamantane (high-frequency line, $\delta_{\mathrm{C}}=$ $38.4 \mathrm{ppm})$, ammonium nitrate $\left(\delta_{\mathrm{N}}=-5.1 \mathrm{ppm}\right.$ for $\left.\mathrm{NO}_{3}{ }^{-}\right)$and brushite $\left(\delta_{\mathrm{P}}=1.2 \mathrm{ppm}\right)$ respectively, but are quoted relative to the usual reference standards, tetramethylsilane, nitromethane and phosphoric acid respectively.

Shielding tensor components are defined according to the notation of Haeberlen ${ }^{7}$;

$$
\left|\sigma_{33}-\sigma_{\text {iso }}\right| \geq\left|\sigma_{11}-\sigma_{\text {iso }}\right| \geq\left|\sigma_{22}-\sigma_{\text {iso }}\right|
$$

The anisotropy is $\zeta=\left|\sigma_{33}-\sigma_{\text {iso }}\right|$, and the asymmetry is $\eta=\left(\sigma_{22}-\sigma_{11}\right) / \zeta$.

$A b$ initio calculations were performed using the experimental geometry, based on the structures derived from neutron diffraction data for (1) and the X-ray diffraction data for (2). All calculations were performed with the Gaussian 94 program $^{8}$ using 6-31g* and 6-311g (2d,p) basis sets and the Hartree-Fock level of theory. The nuclear magnetic shielding tensors were calculated by the GIAO theory ${ }^{9,10}$. The B3LYP hybrid density functional method, which allows for electron correlation, has been used as incorporated in the Gaussian 94 program. For the basis sets used herein, density functional methods tend to predict NMR values that are deshielded when compared to experiment and to Hartree-Fock methods.

\section{Crystallographic Data and Electronic Structure}

Single-crystal X-ray diffraction measurements have been made $e^{5,6}$ on both compounds and the structures solved. For the parent iminophosphorane, neutron diffraction experiments, performed at $20 \mathrm{~K}$, have also been published ${ }^{6}$, giving more accurate positions for the hydrogen nuclei.
Table 1 summarises the bond distances involving phosphorus. The P-N bond is significantly shorter for the parent iminophosphorane than for the bromide salt. Thus a resonance structure $\mathrm{Ph}_{3} \mathrm{P}^{+}-\mathrm{NH}_{2}$ is important for the latter, implying the existence of a lone pair on nitrogen. The local molecular symmetries about $\mathrm{P}$ for (1) and (2) found from crystallography have implications for the ${ }^{13} \mathrm{C}$ NMR spectra discussed below. In (1), each molecule has local $\mathrm{C}_{1}$ symmetry about $\mathrm{P}$ [i.e. all three ipso carbon atoms of the phenyl groups are different, Scheme 1(a)], whereas in (2) local $\mathrm{C}_{\mathrm{s}}$ symmetry results from protonation of the imine $\mathrm{N}$ atom [i.e. two ipso carbon atoms of the phenyl groups (C') are equivalent, Scheme 1(b)].

\section{NMR Results, GIAO Calculations and Discussion}

The ${ }^{31} \mathrm{P}$ CPMAS spectrum of the bromide is shown in Fig. 1. There is a single centreband at a chemical shift $\delta_{\mathrm{P}}=$ $34.8 \mathrm{ppm}$, close to that observed for a solution in deuterated chloroform $\left(\delta_{\mathrm{P}}=36.2 \mathrm{ppm}\right)$. There is, however, a 1:2 splitting caused by residual dipolar coupling to the quadrupolar ${ }^{14} \mathrm{~N}$ nucleus ${ }^{11}$ (see below). Simulation of the spinning-sideband manifold gave shielding tensor information listed in Table 2, as are the corresponding data for the parent iminophosphorane. For the latter, solution-state measurements gave $\delta_{\mathrm{P}}=17.5$ and $22 \mathrm{ppm}$ when toluene and THF were used as solvents, respectively. It is clear that there are no substantial molecular structural differences between the solution and solid states of these compounds, although for 1 weak intermolecular $\mathrm{C}$ - H...N interactions were inferred from the neutron data ${ }^{6}$, which are unlikely to be maintained in solution. Gaussian 94 GIAO calculations were per-

Table 1. Bond lengths from X-ray crystallographic data at $150 \mathrm{~K}(1)^{6}$ and $153 \mathrm{~K}(\mathbf{2})^{5}$.

\begin{tabular}{lcc}
\hline Compound & $\mathrm{P}-\mathrm{N} / \AA$ & $\mathrm{P}-\mathrm{C} / \AA$ \\
\hline $\mathbf{1}$ & $1.562(3)$ & $1.818(3), 1.817(3), 1.810(3)$ \\
$\mathbf{2}$ & $1.615(3)$ & $1.797(3), 1.791(3), 1.791(3)$ \\
\hline
\end{tabular}

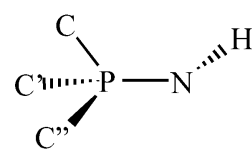

1

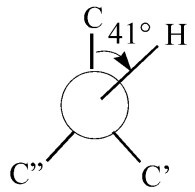

(a)

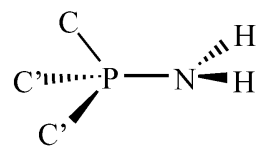

2

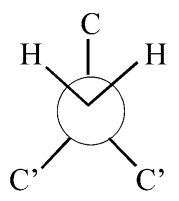

(b)

Scheme 1. 
Table 2. Chemical shift and shielding data from ${ }^{31} \mathrm{P}$ CPMAS NMR and Gaussian 94 calculations (at the hf/6-31g* level).

\begin{tabular}{|c|c|c|c|c|c|c|}
\hline \multirow[t]{2}{*}{ Compound } & \multirow[t]{2}{*}{$\delta_{\text {iso }} / \mathrm{ppm}$} & \multirow[t]{2}{*}{$\sigma_{\text {iso }} / \mathrm{ppm}^{\mathrm{d}}$} & \multicolumn{2}{|c|}{$\zeta / \mathrm{ppm}$} & \multicolumn{2}{|c|}{$\eta$} \\
\hline & & & Expt. $^{\mathrm{c}}$ & Calc. & Expt. $^{\mathrm{c}}$ & Calc. \\
\hline $1^{a}$ & $21.8^{\mathrm{e}}$ & 402.5 & $107(1.3)$ & 98 & $0.19(0.03)$ & 0.24 \\
\hline $2^{\mathrm{b}}$ & $34.8^{f}$ & 392.9 & $42(0.5)$ & 32 & $0.52(0.01)$ & 0.56 \\
\hline
\end{tabular}

${ }^{\mathrm{a}}$ Imino(triphenyl)phosphorane.

${ }^{\mathrm{b}}$ Amino(triphenyl)phosphonium bromide.

${ }^{\mathrm{c}}$ From fitting of spinning sideband intensities. Estimated statistical errors in brackets.

${ }^{\mathrm{d}}$ Calculated absolute shielding (see the text).

${ }^{\mathrm{e}}$ Individual components: -85.2(1.3), 65.1(1.8) and 85.5(1.9) ppm.

${ }_{\mathrm{f}}^{\mathrm{f}}$ Individual components: -7.2(0.5), 44.9(0.3) and 66.7(0.4) ppm.

formed at the hf/6-31g* level and are also reported in Table 2. The agreement between the observed and calculated values of the shielding anisotropies and asymmetries for both $\mathbf{1}$ and $\mathbf{2}$ is remarkably good. Such calculations gave absolute isotropic shielding constants of 392.9 and 402.5 ppm for the bromide salt and parent iminophosphorane respectively. To relate these to the chemical shift scale, the absolute shielding of the reference compound, $\mathrm{H}_{3} \mathrm{PO}_{4}$ was taken to be $328.4 \mathrm{ppm}^{12}$, giving shifts of $\delta_{\text {iso }}=-64.5$ and $-74.1 \mathrm{ppm}$ respectively (i.e. considerably in error). When the basis set was increased to the $6-311 \mathrm{~g}(2 \mathrm{~d}, \mathrm{p})$ level, these values improved to -1 and -9 ppm respectively. Use of the B3LYP hybrid density functional method gave even better calculated values (+61 and $+47 \mathrm{ppm}$ respectively) for the isotropic shifts, though they are deshielded in both cases compared to the experimental values. It may be seen that the errors in the simpler treatment $\left(\mathrm{hf} / 6-31 \mathrm{~g}^{*}\right)$ are substantially lower for the shielding anisotropy and asymmetry,

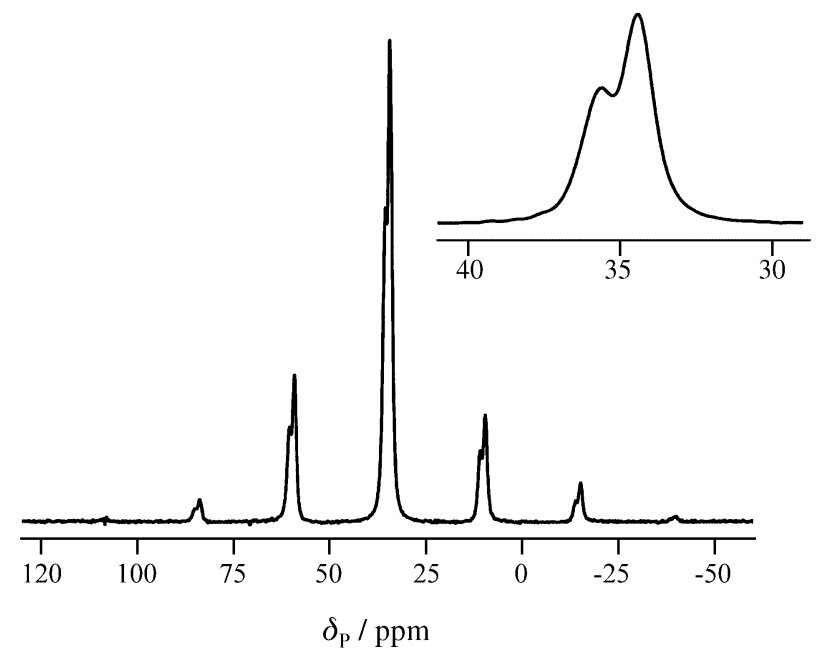

Figure 1. Phosphorus-31 CPMAS NMR spectrum of amino(triphenyl)phosphonium bromide, obtained at ambient probe temperature with sample spinning at $2 \mathrm{kHz}$ and high-power proton decoupling. The inset shows the sum of all the sidebands (plus the centreband) and illustrates the splitting arising from residual dipolar coupling. The acquisition parameters were: pulse duration $4.5 \mu \mathrm{s}$, contact time $1 \mathrm{~ms}$, recycle delay $30 \mathrm{~s}$, and number of transients 32 . which use internal differences, than for the isotropic parameters.

The static ${ }^{31} \mathrm{P}$ spectrum of the bromide salt is illustrated in Fig. 2. This was acquired with $\mathrm{CP}$, a Hahn echo, and proton decoupling during acquisition. The general shape makes it clear that the asymmetry is non-zero and that there is some broadening from homonuclear (P,P) dipolar coupling, making the turning points indistinct. As the crystal structure is known, the $\left({ }^{31} \mathrm{P},{ }^{14} \mathrm{~N}\right)$ dipolar coupling constant can be calculated at $\mathrm{D}=835 \mathrm{~Hz}$. We assume the indirect coupling tensor is negligible $\left(\mathrm{J}_{\text {iso }}=32.9 \mathrm{~Hz}\right.$ for $N$ phenyl(triphenyl)iminophosphorane ${ }^{13}$ ). The spectrum was iteratively fitted, with variation of the shielding anisotropy and asymmetry, the intrinsic linewidth and the Euler angles $\left(\alpha^{\mathrm{S}}\right.$ and $\left.\beta^{\mathrm{S}}\right)$ relating the shielding and dipolar tensors. These parameters are equivalent to the polar angles of the P-N internuclear vector in the principal axis system of the shielding tensor, with $\alpha^{\mathrm{S}}$ being defined relative to $\sigma_{22}$. The result is shown in Fig. 2. It is found that $\zeta=45 \mathrm{ppm}$ and $\eta=0.78$, which are in reasonable agreement with the results from the spinning-sideband analysis. The result for $\eta$

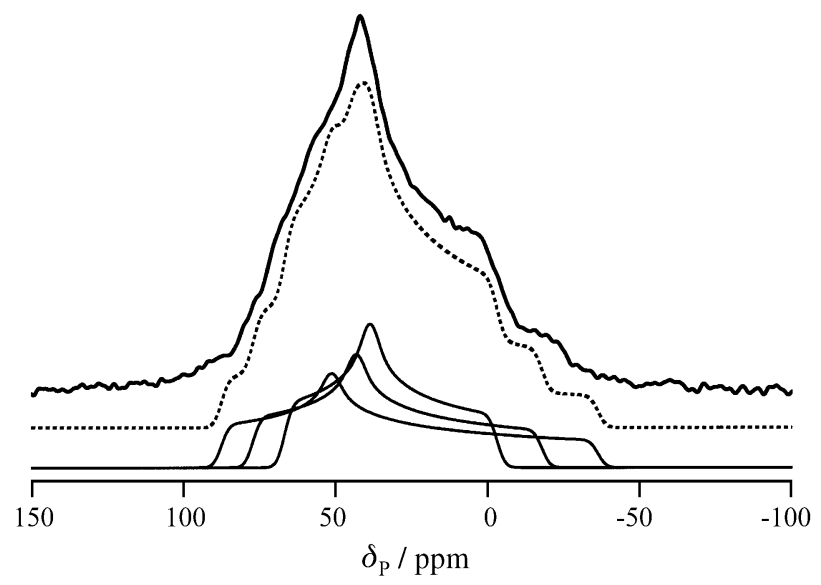

Figure 2. Static ${ }^{31} \mathrm{P}$ spectrum of amino(triphenyl)phosphonium bromide, obtained at ambient probe temperature, with a full simulation (dashed line) and the simulated subspectra (full lines) below. Acquisition parameters were: pulse duration $4.5 \mu \mathrm{s}$, contact time $1 \mathrm{~ms}$, echo time $40 \mu \mathrm{s}$, recycle delay $10 \mathrm{~s}$ and number of transients 1024 . The intrinsic linewidth was found to be $400 \mathrm{~Hz}$. 
is likely to have a substantial uncertainty. The shielding and dipolar tensors are found to be mutually oriented with angles $\beta^{\mathrm{S}}=30^{\circ}$ and $\alpha^{\mathrm{S}}=70^{\circ}$. Changing these angles by more than $10^{\circ}$ makes a noticeable difference to the fit, though the angle $\alpha^{\mathrm{S}}$ is less sensitive to changes than $\beta^{\mathrm{S}}$. The hf $/ 6-31 \mathrm{~g}^{*}$ calculations give $\beta^{\mathrm{S}}=30^{\circ}$ and $\alpha^{\mathrm{S}}=2^{\circ}$, indicating that there is effective (local) $\mathrm{C}_{\mathrm{S}}$ symmetry for the $\mathrm{P}-\mathrm{N}$ bond. From the fitted values for these angles and the $a b$ initio calculated orientation in the molecular frame, it is clear that the largest component of the shielding tensor lies in the plane of the N-P-C(unique) atoms and approximately perpendicular to the unique $\mathrm{P}-\mathrm{C}$ bond. The component $\sigma_{22}$ also lies in this N-P-C plane within experimental error (according to the $a b$ initio calculations), whilst $\sigma_{11}$ is perpendicular to the plane. For the parent iminophosphorane $\beta^{\mathrm{S}}$ was found to be zero within experimental error (so that experimentally $\alpha^{\mathrm{S}}$ becomes meaningless), $\sigma_{33}$ being essentially along the $\mathrm{P}-\mathrm{N}$ bond. The $a b$ initio calculations suggest that, from a viewpoint down the N-P bond, $\sigma_{11}$ lies at a dihedral angle of $12^{\circ}$ to P-C (see Scheme $1(\mathrm{a})$ ) and $30^{\circ}$ to $\mathrm{N}-\mathrm{H}$.

The splittings, $s$, in the ${ }^{31} \mathrm{P}$ spectrum arising from residual dipolar coupling to ${ }^{14} \mathrm{~N}$ may be calculated using perturbation theory by the equation ${ }^{11}$ :

$$
s=\left(9 D \chi / 20 v_{\mathrm{N}}\right)\left(3 \cos ^{2} \beta^{\mathrm{D}}-1+\eta \sin ^{2} \beta^{\mathrm{D}} \cos 2 \alpha^{\mathrm{D}}\right)
$$

where $D$ is the dipolar coupling constant, $\chi$ is the quadrupolar coupling constant, and $\eta$ is the quadrupolar asymmetry, while $\alpha^{\mathrm{D}}$ and $\beta^{\mathrm{D}}$ are the Euler angles of the P-N vector in the quadrupolar principal axes. There is some mutual compensation between changes in $\chi$ and $\beta^{\mathrm{D}}$. Measured values of s are 101 and $75 \mathrm{~Hz}$, with estimated errors of $\pm 20 \mathrm{~Hz}$ (the intrinsic linewidths of the ${ }^{31} \mathrm{P}$ peaks being ca. $60 \mathrm{~Hz}$ ), for the bromide and parent iminophosphorane respectively. Both splittings are found to be positive, i.e. the smaller component lies at the higher frequency.

Calculations with the 6-31g* basis set were used to estimate the electric field gradients at the nitrogen nuclei of the bromide salt and parent iminophosphorane and were found to be 0.92 and -0.71 atomic units respectively. The value of the quadrupole moment of ${ }^{14} \mathrm{~N}$ has been taken ${ }^{14}$ as $1.61 \times 10^{-30} \mathrm{~m}^{2}$, giving the quadrupole coupling constant data (including orientation information) quoted in Table 3. The calculated values of $s$ are in reasonable agreement with the experimental data, given the errors involved in both experiment and $a b$ initio calculations. For the bromide salt, the calculated value of $\chi$ is negative, in agreement with the experimental measurement. This situation occurs because the electric field gradient arises mainly from a lone pair of electrons (in the resonance form with a P-N single bond); the orientation revealed by the calculations, $\beta^{\mathrm{D}}=95^{\circ}$, is in the direction where a lone pair would be expected. In this case $\chi$ (i.e. $s$ ) has been underestimated, indicating that the lone pair contribution may be larger than the calculations suggest. For the parent iminophosphorane the largest component of the EFG is aligned at an angle of $27^{\circ}$ to the P-N bond, which is approximately where the lone pair of electrons (or the average of the two lone pairs for the resonance form $\left.\mathrm{Ph}_{3} \mathrm{P}^{+}-\mathrm{N}^{-} \mathrm{H}\right)$ is expected.

Figure 3 shows carbon-13 CPMAS spectra for the bromide under different conditions. The dipolar-dephased spectrum (Fig. 3b) shows clearly that one phenyl group is substantially different from the other two, as expected from the diffraction evidence. The fact that the observed doublet splittings arise from $(\mathrm{P}, \mathrm{C})$ coupling is proved by triplechannel experiments, i.e. observation of the dipolar-

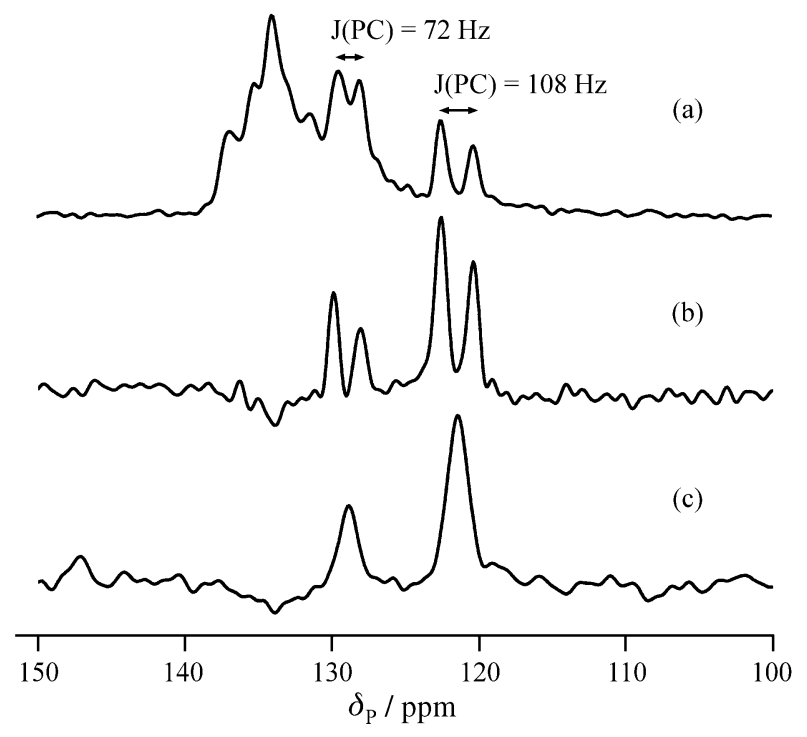

Figure 3. Carbon-13 CPMAS spectra of amino(triphenyl)phosphonium bromide, obtained at ambient probe temperature: (a) full spectrum, with ${ }^{1} \mathrm{H}$ decoupling during acquisition; (b) dipolar-dephased spectrum, with ${ }^{1} \mathrm{H}$ decoupling during acquisition; (c) dipolar-dephased spectrum, with both ${ }^{1} \mathrm{H}$ and ${ }^{31} \mathrm{P}$ decoupling during acquisition. Acquisition parameters were: pulse duration $5 \mu \mathrm{s}$, contact time $1 \mathrm{~ms}$, dephasing time $50 \mu \mathrm{s}$, recycle delay $5 \mathrm{~s}$, spin rate $4 \mathrm{kHz}$, and number of transients (a,b) 1500, (c) 1328 .

Table 3. Residual dipolar coupling information ${ }^{\mathrm{a}}$.

\begin{tabular}{lccccccc}
\hline Compound & $D / \mathrm{Hz}^{\mathrm{b}}$ & $\chi / \mathrm{MHz}$ & $\eta$ & $\alpha^{\mathrm{D}}$ & $\beta^{\mathrm{D}}$ & $s / \mathrm{Hz} \mathrm{Calc.}$ & $s / \mathrm{Hz}$ Expt. \\
\hline $\mathbf{1}$ & 923 & 2.71 & 0.67 & -27 & $27^{\circ}$ & 114 & 75 \\
$\mathbf{2}$ & 835 & -3.53 & 0.25 & 0 & $95^{\circ}$ & 66 & 101 \\
\hline
\end{tabular}

${ }^{\mathrm{a}} \chi, \eta, \alpha^{\mathrm{D}}, \beta^{\mathrm{D}}$, and thence the experimental value of $s$, are computed using the hf/6-31g* level of theory.

${ }^{\mathrm{b}}$ Calculated from the crystal structure. 
dephased ${ }^{13} \mathrm{C}$ spectrum with simultaneous decoupling of ${ }^{1} \mathrm{H}$ and ${ }^{31} \mathrm{P}$ (Fig. 3c). The ipso-carbon isotropic chemical shifts are $\delta_{\mathrm{C}}=121.4$ and $128.7 \mathrm{ppm}$, with $(\mathrm{P}, \mathrm{C})$ isotropic coupling constants 108 and $72 \mathrm{~Hz}$ in magnitude respectively. The chemical shifts of the remaining carbon nuclei are not clear. For the parent iminophosphorane the ${ }^{13} \mathrm{C}$ spectra have very poor signal-to-noise $(\mathrm{S} / \mathrm{N})$ ratios because a long recycle delay is required for relaxation, so definitive data are not readily available. However, the double-decoupled dipolar-dephased spectrum shows three sharp peaks at $\delta_{\mathrm{C}}=128.3,130.6$ and $135.6 \mathrm{ppm}$, in agreement with the existence of three non-equivalent phenyl groups.

The ${ }^{15} \mathrm{~N}$ CPMAS spectrum of the bromide has been measured using the Varian UnityPlus 300 spectrometer (contact time $4 \mathrm{~ms}$, recycle delay $45 \mathrm{~s}$ ). Accumulation of the signal over a full day was barely sufficient to measure the isotropic chemical shift as $\delta_{\mathrm{N}}=-340 \mathrm{ppm}$, and no shielding tensor information was accessible - no spinning sidebands were visible, probably because of the low S/N. $A b$ initio calculations yield the data in Table 4 . The values for the shielding anisotropies and asymmetries may be expected to be more reliable than the isotropic data.

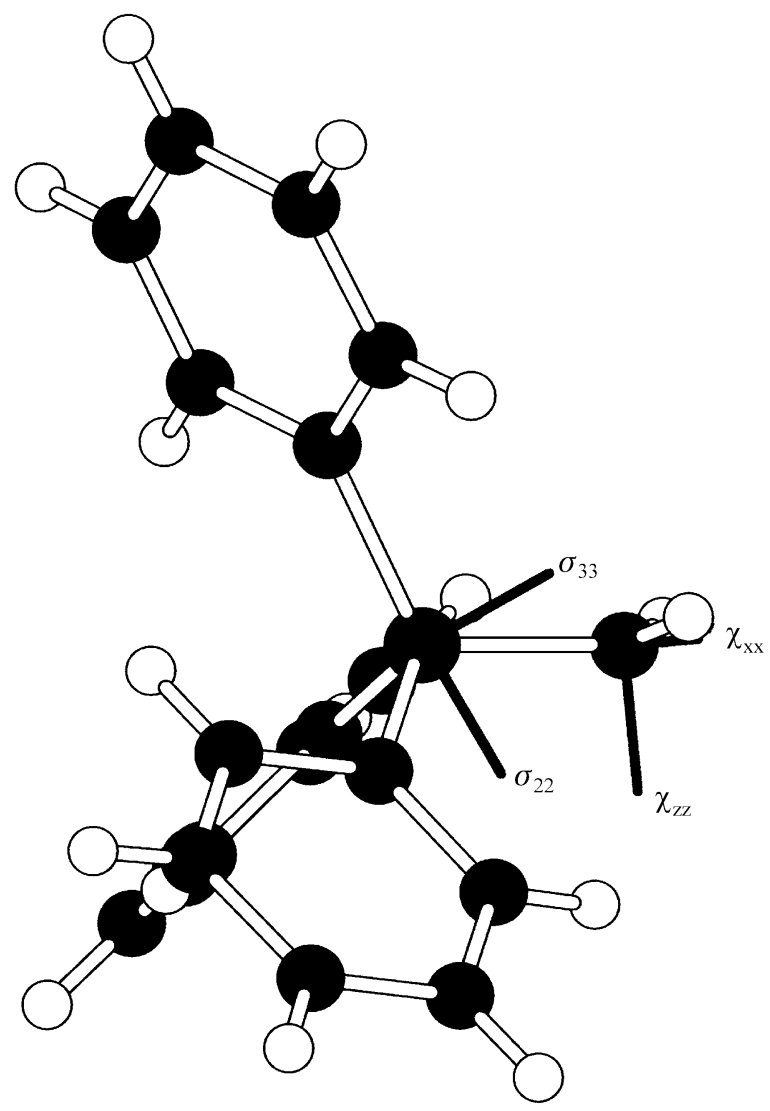

Figure 4. Structure of amino(triphenyl)phosphonium bromide with directions of the shielding and quadrupolar tensors superimposed.
Table 4. Shielding information for ${ }^{15} \mathrm{~N}$, obtained from ab initio calculations at the hf/6-31g* level.

\begin{tabular}{lcccc}
\hline Compound & $\sigma_{\text {iso }} / \mathrm{ppm}$ & $\delta_{\text {iso }} / \mathrm{ppm}^{\mathrm{a}}$ & $\zeta_{\text {iso }} / \mathrm{ppm}$ & $\eta$ \\
\hline $\mathbf{1}$ & 246.5 & -362.2 & 57 & 0.30 \\
$\mathbf{2}$ & 283.1 & -398.8 & 26 & 0.35 \\
\hline
\end{tabular}

${ }^{\mathrm{a}}$ Based on a shielding for $\mathrm{NH}_{3}$ of $264.5 \mathrm{ppm}$ (at a chemical shift of -380.2 ppm) ${ }^{15,16}$.

\section{Conclusions}

Insight into the molecular and electronic structure of imino(triphenyl)phosphorane and its hydrobromide salt in their solid states has been provided by detailed analyses of their CPMAS ${ }^{13} \mathrm{C}$ and ${ }^{31}$ PNMR spectra. Molecular orbital calculations, based on known crystal structures, give good agreement with experimental data for ${ }^{31} \mathrm{P}$ shielding anisotropy and asymmetry, and for ${ }^{14} \mathrm{~N}$ nuclear quadrupole coupling (accessed via residual dipolar coupling effects in ${ }^{31} \mathrm{P}$ spectra). The orientations of the tensors in the molecular frame for the bromide are shown in Fig. 4. Dipolar dephasing experiments on ${ }^{13} \mathrm{C}$ spectra are in accord with the crystal structures, and $\left({ }^{31} \mathrm{P},{ }^{13} \mathrm{C}\right)$ coupling is proved by triple-channel experiments.

\section{Acknowledgements:}

Two of us (JCC and RDP) thank the U.K. Engineering and Physical Sciences Research Council (EPSRC) for studentships and to I.C.I. for scholarships. We are also grateful to EPSRC for access to the Solid-state NMR Service based at Durham.

\section{References}

1. (a) Armstrong, D.R.; Davidson, M.G.; Moncrieff, D. Angew. Chem. Int. Ed. Engl. 1995, 34, 478; (b) Batsanov, A.S.; Bolton, P.D.; Copley, R.C.B.; Davidson, M.G.; Howard, J.A.K.; Lustig, C.; Price, R.D. J.Organomet. Chem. 1998, 550, 445; (c) Batsanov, A.S.; Davidson, M.G.; Howard, J.A.K.; Lamb, S.; Lustig, C.; Price, R.D. J.C.S. Chem. Comm. 1997, 1211.

2.Power, W.P.; Wasylishen, R.E.; Curtis, R.D. Can. J. Chem. 1989, 67, 454.

3. Power, W.P. J. Am. Chem. Soc. 1995, 117, 1800.

4. Gudat, D.; Niecke, E.; Grossmann, G.; Krüger, K. Magn. Reson. Chem. 1999, 37, 43.

5. Phol, E.; Gosink, H.J.; Herbst-Irmer, R.; Noltemeyer, M.; Roesky, H.W.; Sheldrick, G.M. Acta Crystallog. C 1993, 49, 1280.

6. Davidson, M.G.; Goeta, A.E.; Howard, J.A.K.; Lehmann, C.W.; McIntyre, G.M.; Price, R.D. J. Organomet. Chem. 1998, 550, 449.

7. Haeberlen, U. Adv. Magn. Reson. Suppl. No. 1 1976, 1. 
8. Gaussian 94, Revision E.2, Frisch, M.J.; Trucks, G.W.; Schlegel, H.B.; Gill, P.M.W.; Johnson, B.G.; Robb, M.A.; Cheeseman, J.R.; Keith, T.; Petersson, G.A.; Montgomery, J.A.; Raghavachari, K.; Al-Laham, M.A.; Zakrzewski, V.G.; Ortiz, J.V.; Foresman, J.B.; Cioslowski, J.; Stefanov, B.B.; Nanayakkara, A.; Challacombe, M.; Peng, C.Y.; Ayala, P.Y.; Chen, W.; Wong, M.W.; Andres, J.L.; Replogle, E.S.; Gomperts, R.; Martin, R.L.; Fox, D.J.; Binkley, J.S.; Defrees, D.J.; Baker, J.; Stewart, J.P.; Head-Gordon, M.; Gonzalez, C.; Pole, J.A. Gaussian Inc., Pittsburgh PA, 1995.

9. Ditchfield, R.; Mol. Phys. 1974, 27, 789.

10. Wolinski, K.; Hinton, J.F.; Pulay, P. J. Am. Chem. Soc. 1990, 112, 8251 .
11. Harris, R.K.; Olivieri, A.C. Prog. NMR Spectry. 1992 , $24,435$.

12. Jameson, C.J.; De Dios, A.; Jameson, A.K. Chem. Phys. Lett. 1990, 167, 575.

13. Pomerantz, M.; Ziemnicka, B.T.; Merchant, Z.M.; Chou, W.; Perkins, W.B.; Bittner, S. J. Org. Chem. 1985, 50, 1757.

14. Brown, R.D.; Head-Gordon, M.P. Mol. Phys. 1987, 61,1183 .

15. Kukolich, S.G. J. Am. Chem. Soc. 1975, 97, 5704.

16. Jameson, C.J.; Jameson, A.K.; Oppusunggu, D.; Wille, S.; Burrell, P.M.; Mason, J. J. Chem. Phys. 1981, 74,81 . 